Original article

\title{
Documentation compliance of in-patient files: A cross sectional study from an east India state
}

\author{
Mohd Aihatram Khan ${ }^{\mathrm{a}, \mathrm{d}, 1}$, Nilima Nilima ${ }^{\mathrm{b}, \mathrm{e}, 1}$, Jackline Prathibha ${ }^{\mathrm{c}}$, Bhaskar Tiwary ${ }^{\mathrm{a}, * *}$, \\ Monika Singh ${ }^{\mathrm{a}, \mathrm{f}}$ \\ ${ }^{a}$ Institute of Health Management Research, Jaipur, India \\ ${ }^{\mathrm{b}}$ All India Institute of Medical Sciences, Delhi, India \\ ${ }^{\mathrm{c}}$ Manipal College of Nursing, Manipal Academy of Higher Education, Manipal, India \\ ${ }^{\mathrm{d}}$ The Mission Hospital, Durgapur, India \\ ${ }^{\mathrm{e}}$ Indian Institute of Public Health, Delhi, India \\ ${ }^{\mathrm{f}}$ CARE India, Bihar, India
}

\section{A R T I C L E I N F O}

\section{Keywords:}

Documentation

Compliance

Inpatient files

Record keeping

\begin{abstract}
A B S T R A C T
Aim: To assess the knowledge, attitude and practices of nurses regarding in-patient file documentation. Background: Documentation is a communication tool that helps in the exchange of information stored between caregivers. Quality documentation promotes structured, consistent and effective communication between healthcare providers. This is a preliminary study on the documentation in tertiary care hospitals for initial steps to be taken by the concerned health officers and decision makers.

Methods: A descriptive cross-sectional study was carried out with a total of 80 respondents who were selected conveniently from a tertiary care hospital in Durgapur. Study utilized a dichotomous self-administered questionnaire. Qualitative characteristics were summarized using frequency and percentages. Chi-square test was used to investigate associations. Statistical Package for Social Sciences (SPSS, Version 25, Licensed by IIHMR University, Jaipur) was used for analysis.

Results: Majority of the nurse $(67.5 \%, \mathrm{n}=54)$ had satisfactory knowledge, attitude \& practice. Chi-squared test of association revealed no significant relation between gender and knowledge, attitude \& practice $\left(\chi^{2}=0.15\right.$, $\mathrm{df}=1$ and $\mathrm{p}=0.697)$. No significant association of knowledge, attitude \& practice was observed with age $\left(\chi^{2}=1.48, \mathrm{df}=2\right.$ and $\left.\mathrm{p}=0.477\right)$ and years of experience $\left(\chi^{2}=2.31\right.$, $\mathrm{df}=1$ and $\left.\mathrm{p}=0.128\right)$.

Conclusion: The nurses appeared to be familiar with the required documentation knowledge. A pressing need was felt to emphasize on all aspects of in-patient documentation under continuous nursing education program. Newly appointed nurses were equally good in documentation compared to their senior counterparts. This study advocates the necessary actions to be taken for enabling nurses for timely documentation of patient details for improved communication with other health workers.
\end{abstract}

\section{Introduction}

Documentation is one of the key areas to determine the standard of care rendered by nurses. ${ }^{1}$ It enhances professional autonomy, critical thinking skills, development of professional knowledge and nursing education. ${ }^{2}$ Documentation is also vital for safe, ethical, and effective nursing practice. Nurses should execute documentation in a way that ensures continuity of care, planning, and liability, as well as in the furtherance and advancement of practices based on evidence. An inpatient file should be factual, accurate, complete \& timely (FACT). ${ }^{3}$ The assessment of the quality of patient care is highly dependent on the caregiver's ability to communicate through documentation as a fragment of the continuum of care. ${ }^{4}$

The concerns associated with poor documentation practices are omitting of medications, improper or double administrations of medicines and the risk of legal harm. Incomplete patient report persistently causes doubts and inculpate in the legal jurisdiction, since only the completely documented medical cases are accepted by the legitimate medical group for verifying and validating medico-legal cases. ${ }^{5}$ A suitable and correct document to show health interventions provided for

\footnotetext{
${ }^{*}$ Corresponding author. Indian Institute of Health Management Research, IIHMR University, Jaipur, India. Mobile: + 919482386283

E-mail address: bhaskar1697@yahoo.com (B. Tiwary).

${ }^{1}$ Authors are equally contributing first authors
} 


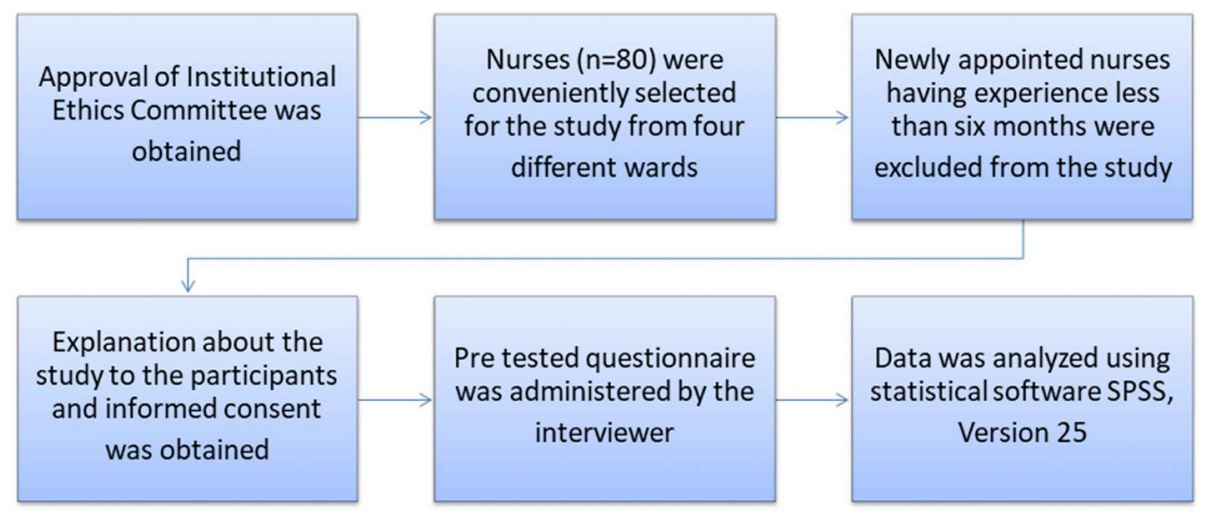

Fig. 1. Flow chart of the study process.

patients is important relating to the legal aspects. ${ }^{6,7}$ Statistics from developed countries showed that $74 \%$ of the cases are errors of healthcare providers which were reported to judicial authorities. ${ }^{8}$

Several standardized frameworks are accessible which aids in nursing documentation which includes charting in a narrative way, approaches which are problem-oriented approaches, clinical pathways, and focus notes. ${ }^{9}$ Nevertheless majority of the nurses still encounter many hurdles in retaining faultless and legally prudent documentation like poor attitudes, lack of knowledge towards nursing documentation, time shortage \& workload. ${ }^{10}$ It is evidenced that approximately $38 \%$ of the time is spent by nurses in documenting patient files in a total working shift. ${ }^{11}$ Documenting in a simple brief, distinct and legally cautious manner can significantly minimize the possibility of misapprehension and apathetic patient outcome which is associated with poor communication in healthcare professionals. ${ }^{12}$

Flawless and virtuous registering of the nursing documentation is one of the key responsibilities of nursing carrier. ${ }^{13-15}$ Indian population lacks primary research on knowledge, attitude \& practices (KAP) of nurses regarding documentation. Hence, there is a need to study the nurse's knowledge, attitude \& practices regarding in-patient file documentation. This is a preliminary study on the documentation in tertiary care hospitals for initial steps to be taken by the concerned health officers and decision-makers.

\section{Methods}

\subsection{Study design}

A cross sectional study was carried out at a tertiary care hospital in Durgapur, India from February 04, 2019 to May 04, 2019.

\subsection{Study participants}

Nurses who play an important role in the documentation process were the study participants. We conveniently selected 80 participants for the study. Newly employed nurses were not allowed to perform the duty independently hence nurses with work experience of at least 6 months were eligible to be recruited in this study. Nurses who were on annual leave, maternity leave, unable to participate in the study due to illness were excluded. Nurses in intensive care units \& in night duty were also excluded. The sampled wards were medicine, surgical, orthopedic \& gynecology because of less workload on nurses in these wards compared to high dependency units \& intensive care units.

\subsection{Study tool}

The study involved the use of pre-tested dichotomous questionnaire developed by the primary investigator with the help of experts in the field of nursing. There were total of 11 questions related to KAP of documentation out of which four questions were of knowledge, three questions of attitude \& four questions regarding practice. The questionnaire was self-administered by the participants. Each correct response was scored as 1 . First 8 questions were basics related to KAP of documentation while the last three questions were relatively difficult. The maximum total KAP score was 11 . Participant's KAP were categorized as non-satisfactory if they scored between 0 and 8 and satisfactory if scored 9 or more.

\subsection{Ethical considerations}

Consent \& permission was obtained from the hospital authority for the study. Informed Consent was obtained from each participant explaining them the aims \& objectives of the research orally. Confidentiality was maintained during the entire course of study.

\subsection{Data analysis}

Numerical characteristics were summarized as mean \pm standard deviation. Categorical variables were summarized using frequencies and percentages. Chi-squared test of association was used to investigate the association between demographical characteristics and KAP. A $\mathrm{p}<0.05$ was considered to be significant throughout. The data was analyzed using Statistical Package of Social Sciences (SPSS, Version 25, Licensed by IIHMR University, Jaipur). (see Fig. 1, Flow chart of the study process)

\section{Results}

A total of 80 nurses were selected \& studied for their knowledge, attitude and practice. The mean age of the respondents was $29.3 \pm 5.5$ years. The mean years of experience was $4.05 \pm 2.38$ years with most $72.5(n=58)$ of the respondents having experience $<5$ years. Almost $(66 \%, n=53)$ of the respondents were female. Most of the respondents fall in the age group of $26-30$ years $(36.3 \%, n=29)$. Majority of the respondents $(43.75 \%, \mathrm{n}=35$ ) had Diploma in Nursing as the highest degree.

Table 1 presents demographic characteristics of the participants.

In knowledge section, majority of the participants $(71.25 \%, \mathrm{n}=57)$ agreed that variability in file documentation impacts patient outcome. Most of the participants $(70 \%, \mathrm{n}=56)$ think that the inpatient files should be FACT. All the participants $(n=80)$ responded that signature plays a vital role in documentation. Majority of the participants $(81.25 \%, \mathrm{n}=65)$ responded that it is necessary to identify differences while shift hand-over in their duty.

While assessing the attitude, it was revealed that most of the respondents $(81.25 \%, \mathrm{n}=80)$ think that documentation enhances transparency, quality, and continuity of care and patient safety. However, $(57.5 \%, \mathrm{n}=46)$ responded that documentation burdens 
Table 1

Demographic Characteristics of the Participants $(\mathrm{N}=80)$.

\begin{tabular}{lll}
\hline Characteristics & Categories & $\mathrm{n}(\%)$ \\
\hline \multirow{2}{*}{ Gender } & Male & $27(33.75)$ \\
Age & Female & $53(66.25)$ \\
& $21-25$ years & $24(30)$ \\
& $26-30$ years & $29(36.3)$ \\
Level of Education & $>30$ years & $27(33.8)$ \\
& Diploma & $35(43.75)$ \\
Years of Experience & B.Sc. Nursing & $30(37.5)$ \\
& Post B.Sc. Nursing & $15(18.75)$ \\
& $<5$ years & $58(72.5)$ \\
& $>5$ years & $22(27.5)$ \\
\hline
\end{tabular}

their work. Majority of the participants $(67.5 \%, \mathrm{n}=54)$ were satisfied with the type of documentation they follow.

Through assessment of practices it was observed that $(72.25 \%$, $\mathrm{n}=57$ ) respondents starts planning nursing care when the patient gets admitted in the healthcare institution. Most of the respondents $(80 \%$, $\mathrm{n}=64$ ) were more comfortable with documenting files later. Findings also revealed that $(66.25 \%, \mathrm{n}=53)$ participants had a practice of documenting events/procedure in advance. All the participants ( $n=80$ ) claimed orienting a common practice whenever a new staff nurse joins.

Table 2 presents knowledge, attitude and practices of nurses regarding in-patient file documentation respectively.

Majority of the nurses $(67.5 \%, n=54)$ had satisfactory KAP. Chisquared test of association revealed no significant relation between gender and $\operatorname{KAP}\left(\chi^{2}=0.15, \mathrm{df}=1\right.$ and $\left.\mathrm{p}=0.697\right)$. No significant association of KAP was observed with age $\left(\chi^{2}=1.48, \mathrm{df}=2\right.$ and $\mathrm{p}=0.477)$ and years of experience $\left(\chi^{2}=2.31, \mathrm{df}=1\right.$ and $\left.\mathrm{p}=0.128\right)$.

\section{Discussions}

The presented study found many findings which adds to the matter of existing knowledge. Documentation and nursing system in response to health care delivery have evolved in recent years and advanced technology has affected its expectations, therefore the quality of documentation reflects standard professional practice. ${ }^{16}$ This study findings are in lying with a study ${ }^{17}$ which reveals that variability documentation leads to lack of clarity among the nursing staff which affects the treatment procedure. A study conducted in Kaduna State concluded that signature plays a vital role in documentation as it helps in identifying the person responsible for a administering a particular treatment or procedure which later helps if there is any medico-legal case. ${ }^{18}$ In the presented study participants understood the importance of signature. Identification of differences while shift handover is important and majority of our participants agreed to this. A similar study quotes that "identification of differences ensures the correct continuity of treatment with a better understanding of what the patient underwent or what was his condition in the past shift". ${ }^{19}$

Nurses with a favorable attitude towards nursing care documentation were more likely to have good nursing care documentation practice. ${ }^{20}$ In the presented study participants responded that documentation burdens their work which is not a good attitude since documentation is an integral part of nursing care. Similar findings were revealed by a study from Iraq which concluded that nurses may consider documentation as their foe, since it steals time from direct patient care. ${ }^{21}$ In the presented study participants think that documentation enhances transparency, quality, and continuity of care and patient safety which shows a genuine attitude of the nurses.

Best practices in nursing are significant because they serve solutions to identified problems and need. ${ }^{22}$ In the presented study, initiation of planning for nursing care was prompt which is indicative of good practice. In this study participants agreed that documenting the files immediately is a good practice however they find it more comfortable to document later. Nurses are not expected to document any procedure in advance as any adverse/beneficial event can occur with the patient when in healthcare institution. The presented study findings were contrast as the participants claimed to practice documenting events in advance. Orientation of nursing staff plays a pivotal role in the competency and retention of newly hired registered nurses. Presented study revealed that effective orientation and precepting programs produce nurses who provide competent, quality patient care and are enculturated as productive members of healthcare team which is in line with study. ${ }^{23}$

$17.78 \%$ nurses from a single hospital were enrolled in the study, which limits the generalizability of our findings. Future research with larger sample size should be taken up in this field to help establish the relationship with a greater precision.

\section{Conclusion}

Majority of participants had satisfactory knowledge, attitude \& practice however significant number of participants were in non-satisfactory category. Sufficient time should be provided to the staff nurses for them to complete the documentation in time, supported by timely audits. Continuous nursing education (CNE) should emphasize on all aspects of in-patient documentation. Young and newly appointed nurses are equally good in documentation compared to their senior counterparts. This study advocates the necessary actions to be taken for enabling nurses for timely documentation of patient details for improved communication with other health workers.

Table 2

Knowledge Attitude and Practice regarding documentation of in-patient files.

\begin{tabular}{|c|c|c|c|}
\hline & \multirow[t]{2}{*}{ Questions } & \multirow{2}{*}{$\frac{\text { Yes }}{\mathrm{n}(\%)}$} & No \\
\hline & & & $\mathrm{n}(\%)$ \\
\hline \multirow[t]{4}{*}{ Knowledge $(\mathrm{n}=80)$} & Does variability in file documentation impacts patient outcome? & $57(71.25)$ & $23(28.75)$ \\
\hline & Do you think in-patient files should be FACT (factual, accurate, complete \& timely)? & $56(70)$ & $24(30)$ \\
\hline & Is signature of documenting nurse responsible while documentation? & $80(100)$ & $0(0)$ \\
\hline & Is it necessary to identify differences while shift hand-over? & $65(81.25)$ & $15(18.75)$ \\
\hline \multirow[t]{3}{*}{ Attitude $(\mathrm{n}=80)$} & Does Documentation burden your works? & $46(57.5)$ & $34(42.5)$ \\
\hline & Do you believe that documentation enhances transparency, quality, continuity of care and patient safety? & $65(81.25)$ & $15(18.75)$ \\
\hline & Are you satisfied with the type of documentation you follow? & $54(67.5)$ & $26(32.5)$ \\
\hline \multirow[t]{4}{*}{ Practice $(n=80)$} & Do you start planning nursing care when patient gets admitted in the hospital? & $57(71.25)$ & $23(28.75)$ \\
\hline & Documentation should be done immediately after any events/procedure? & $16(20)$ & $64(80)$ \\
\hline & Do you document any procedure/events in advance? & $53(66.25)$ & $27(33.75)$ \\
\hline & Do you orient new staff regarding documentation practices at the time of joining? & $80(100)$ & 0 \\
\hline
\end{tabular}




\section{Authors contributions}

Mohd. Aihatram Khan \& Bhaskar Tiwary were responsible for study conception, design \& data collection. Jackline Prathibha \& Monika Singh formed the manuscript. Nilima Nilima provided statistical expertise, critically revised the manuscript and formed final draft along with Mohd. Aihatram Khan.

\section{Declaration of competing interest}

Authors claim no conflicts of interest.

\section{Acknowledgement}

Authors are thankful to the nurses for their cooperation. The authors also recognize the support from the administration of the hospital and Dr. Tanjul Saxena (Co-founder and Independent Consultant-Academics \& Training, Meta Aide). Authors would also like to acknowledge Mr. Rahul Singh (B. Tech, Mechanical Engineering) for proofreading this article.

\section{References}

1. Keenan GM, Yakel E, Tschannen D, Mandeville M. Documentation and the nurse care planning process. Patient Safety and Quality: An Evidence-Based Handbook for Nurses. Agency for Healthcare Research and Quality (US); 2008.

2. Parandeh A, Khaghanizade M, Mohammadi E, Mokhtari-Nouri J. Nurses' human dignity in education and practice: an integrated literature review. Iran J Nurs Midwifery Res. 2016;21(1):1.

3. Taiye, B. H. Knowledge and Practice of Documentation Among Nurses in Ahmadu Bello University Teaching Hospital (Abuth) Zaria, Kaduna State.

4. Nakate G, Dahl D, Drake KB, Petrucka P. Knowledge and attitudes of select Ugandan nurses towards documentation of patient care. Afr J Nurs Midwifery. 2015;2(1) 056.

5. Hogan MA. Fundamentals of Nursing: Caring and Clinical Judgement. Saunders; 2003.

6. Ghazanfari Z, Sheykhpour-khani M, Haghdoost AA. Nurse's knowledge and practice of the principles of nursing documentation at hospitals of Kerman University of
Medical Sciences. Iran J Nurs. 2009;22(59):15-22.

7. Hameed RY, Allo RR. Assessment of nurses' knowledge about nursing documentation. kufa J Nurs Sci. 2014;4(1):137-144.

8. Aghdam ARM, Jasemi M, Rahmani A. Quality of Nursing Documents in Medical-Surgical Wards of Teaching Hospitals Related to. vol. 14. Tabriz University of Medical Sciences; 20092.

9. Blair W, Smith B. Nursing documentation: frameworks and barriers. Contemp Nurse. 2012;41(2):160-168.

10. Petkovšek-Gregorin R, Skela-Savič B. Nurses' perceptions and attitudes towards documentation in nursing. Obzornik zdravstvene nege. 2015;49(2).

11. Yeung MS, Lapinsky SE, Granton JT, Doran DM, Cafazzo JA. Examining nursing vital signs documentation workflow: barriers and opportunities in general internal medicine units. J Clin Nurs. 2012;21(7-8):975-982.

12. Wang N, Hailey D, Yu P. Quality of nursing documentation and approaches to its evaluation: a mixed-method systematic review. J Adv Nurs. 2011;67(9):1858-1875

13. Björvell C, Wredling R, Thorell-Ekstrand I. Improving documentation using a nursing model. J Adv Nurs. 2003;43(4):402-410.

14. Daskein R, Moyle W, Creedy D. Aged-care nurses' knowledge of nursing documentation: an Australian perspective. J Clin Nurs. 2009;18(14):2087-2095.

15. Sheykhpourkhani M, Haghdoust AA. Relationship between Nurse's Knowledge and Practice Regarding the Principles of Nursing Documentation Among Nurses Affiliated to Kerman Medical University Hospitals. 2010; 2010.

16. Okaisu EM, Kalikwani F, Wanyana G, Coetzee M. Improving the quality of nursing documentation: an action research project. Curationis. 2014;37(2):1-11.

17. Allan J, Englebright J. Patient-centered documentation: an effective and efficient use of clinical information systems. J Nurs Adm: J Nurs Adm. 2000;30(2):90-95.

18. Taiye BH. Knowledge and Practice of Documentation Among Nurses in Ahmadu Bello University Teaching Hospital (Abuth) Zaria, Kaduna State.

19. Hagshenas Mojaveri M, Sohrabi F, Aziznejad Roshan P, Hajiahmadi M. Audit nursing reports in intubated neonates admitted in neonatal intensive care unit of Ayatollah Rouhani Hospital, Babol, Iran. Caspian J Pediatr. 2017;3(1):183-188.

20. Moody LE, Slocumb E, Berg B, Jackson D. Electronic health records documentation in nursing: nurses' perceptions, attitudes, and preferences. Comput Inf Nurs. 2004;22(6):337-344

21. Al-Ali NM, Al Faouri I, Al-Niarat TF. The impact of training program on nurses' attitudes toward workplace violence in Jordan. Appl Nurs Res. 2016;30:83-89.

22. Gutierres LDS, Santos JLGD, Peiter CC, Menegon FHA, Sebold LF, Erdmann AL. Good practices for patient safety in the operating room: nurses' recommendations. Rev Bras Enferm. 2018;71:2775-2782.

23. Beecroft P, Hernandez AM, Reid D. Team preceptorships: a new approach for precepting new nurses. J Nurs Prof Dev. 2008;24(4):143-148. 